\title{
Correlates of Depressive Symptomatology in African American Breast Cancer Patients
}

\author{
Vanessa B. Sheppard, Ph.D. ${ }^{1}$, Adana A. Llanos, Ph.D. ${ }^{2}$, Alejandra Hurtado de Mendoza, \\ Ph.D. ${ }^{1}$, Teletia R. Taylor, Ph.D. ${ }^{3}$, and Lucile L. Adams-Campbell, Ph.D. ${ }^{2}$ \\ ${ }^{1}$ Department of Oncology, Lombardi Comprehensive Cancer Center, 3300 Whitehaven St., NW \\ Suite 4100 Washington, DC 20007 \\ ²Lombardi Comprehensive Cancer Center, Research Building E 501, 3970 Reservoir Road, NW, \\ Washington, DC 20057 \\ ${ }^{3}$ Howard University Cancer Center, 2041 Georgia Avenue, NW, Washington, DC 20060
}

\begin{abstract}
Purpose-This study assessed the levels of depressive symptomatology in African Americans women with breast cancer compared to those of women without breast cancer and examined demographic, psychosocial, and clinical factors were correlated with depression.

Methods-A total of 152 African American women were recruited from Washington DC and surrounding suburbs. Breast cancer patients ( $\mathrm{n}=76$ cases) were recruited from a healthcare center and women without cancer were recruited from health fairs ( $\mathrm{n}=76$ comparison). We assessed depression, psychosocial variables (ego strength and social support) and socio-demographic factors from in-person interviews. Stage and clinical factors were abstracted from medical records. Independent sample t-test, chi square test, ANOVA, and multiple regression models were used to identify differences in depression and correlates of depression among the cases and comparison groups.
\end{abstract}

Results-Women with breast cancer reported significantly greater levels of depression $(\mathrm{m}=11.5$ $\mathrm{SD}=5.0)$ than women without breast cancer $(\mathrm{m}=3.9 ; \mathrm{SD}=3.8)(\mathrm{p}<.001)$. Higher cancer stage (beta $=.91$ ) and higher age (beta $=.11$ ) were associated with depression in the breast patients, explaining $84 \%$ of the variance. In the comparison group, ego strength and tangible support were inversely associated with depressive symptoms, accounting for $32 \%$ of the variance.

Conclusions-Women with more advanced disease may require interdisciplinary approaches to cancer care (i.e., caring for the whole person).

Implications for cancer survivors-Depression is often under-recognized and under-treated in African American breast cancer patients. Understanding the factors related to depression is necessary to integrate psychosocial needs to routine cancer care to improve survivors' quality of life.

\footnotetext{
Address correspondence to: Vanessa B. Sheppard, Ph.D. Georgetown University, Cancer Prevention and Control Program Lombardi Comprehensive Cancer Center 3300 Whitehaven St., NW Suite 4100, Washington, DC 20007 vls3@ georgetown.edu, Telephone: 202-687-7036, Fax: 202-687-0305 .

Statement of Conflict of Interest The authors declare that they have not conflicts of interest.

Statement of Original Publication The authors declare that this manuscript contains original unpublished work and is not being submitted for publication elsewhere at the same time.
} 


\section{Keywords}

Breast cancer; oncology; depression; African American; ego strength; social support

\section{Introduction}

Breast cancer is the leading cancer diagnosed in African American women and is the second leading cause of cancer death [1]. Furthermore, African American women have the highest age-adjusted rates of breast cancer mortality [1,2]. A diagnosis of breast cancer can cause varying degrees of psychological distress among women and oftentimes there is the potential for future mental health issues and reduced quality of life if it is unresolved [3,4]. Furthermore, depression in breast cancer patients has been related to lower medication treatment adherence and higher mortality rates [5-7]. Despite depression's detrimental impact in breast cancer prognosis, this condition is rarely recognized and treated [7]. Thus, identification of factors that are related to depression among women with breast cancer is important to help clinicians address and integrate psychosocial needs into routine cancer care, as recommended by the New Quality Standard [8]. This endeavor is especially important for African American breast cancer patients who face a worse prognosis after diagnosis than other racial and ethnic groups and who are understudied compared to their white counterparts [9].

There is some evidence to suggest that depression prevalence may vary by race and ethnicity though data are equivocal and research in this area has been scarce [10-12]. A woman's response to her diagnosis is complex and may be the result of interaction of several factors including her internal capacities as well as her interactions with others. Therefore, consequences of negative life events, such as breast cancer may differ between African American and White women.

A woman's psychosocial response to breast cancer diagnosis has been examined, for the most part, through administration of personality inventories and structured clinical interviews. However, limited empirical data exist that assess the level of depression symptoms in African American women with breast cancer or whether these rates are similar to African American women in the general community without breast cancer. The need for attention to mental health concerns of African American women has been noted in qualitative studies [13] but specific aspects are lacking such as examination of ego strength and the role of social support in mediating depression. Therefore, it is important to investigate African American women's psychological response to breast cancer status. This will provide a better understanding of the correlates of depressive symptoms in this group, which may help to reduce disparities in cancer outcomes.

Existing studies have not examined the role that specific personality traits such as ego strength play in the manifestation of depressive symptomatology in response to breast cancer diagnosis in African American women. Ego strength, a concept widely examined in the field of psychology, has been defined as a measure of the "internal psychological equipment or capacities that an individual brings to his or her interactions with others and with the social environment."[14] (p.70). Because therapists and researchers have utilized ego strength to predict psychological adjustment and the success of patients in psychotherapy [15-17], it seems prudent to examine whether different levels of ego strength can assist in predicting the development of depressive symptoms in African American breast cancer patients. 
Another important element related to the psychological response to breast cancer diagnosis is social support. Social support often functions as a buffer from negative psychological reactions to both mental and physical illness [18]. Several investigators have examined the valuable role that social support plays in assisting breast cancer patients' adjustment to diagnosis [19-29] and have demonstrated an association between social support and depression among patients with the disease. Researchers have also found that perceived adequacy of support is a positive predictor of psychological outcome and response to breast cancer diagnosis [21,30-32]. Some studies suggest that the dynamics of social support may vary by race. One study [21] found a race-relationship between perceived social support and adjustment and another study [33] showed that African Americans and White breast cancer patients tended to seek different sources of support.

The National Comprehensive Cancer Network (NCCN) [34] recommends that oncologists routinely assess distress in cancer patients yet there are scientific gaps in knowledge about the level of depressive symptomology in African American women with breast cancer particularly in comparison to women without breast cancer. Although Black women tend have an earlier age of onset of breast cancer compared to White women [35], there is paucity of research with younger women ( $<50$ years old). The current study begins to address some of these gaps by addressing the following: (1) what are the levels of depressive symptomatology in young African American women with breast cancer? (2) does the level of depressive symptoms vary according to selected demographic factors (age, marital status, income level, occupation, education)? and (3) how much variance in depressive symptomatology is explained by ego strength, stage of breast cancer, and social support?

\section{Methods}

\section{Design and Study Participants}

Approval for this study was obtained from the Institutional Review Board of the NIH, Georgetown University Medical Center, and Howard University. This study compared depression in women diagnosed with breast cancer to those in the general community. The study focused on women between the age of 40 and 50 to capture women that were old enough to have mammography recommended and also to account for the fact that African American women tend to have an earlier onset of breast cancer yet younger breast cancer patients are underrepresented in the literature. Breast cancer cases were eligible if they were: African American between 40-50 years old, diagnosed with breast cancer within 12 months of data collection; not currently being treated for depression; and not currently engaged in abuse of illicit drugs. Breast cancer cases (stage I-IV) were identified from pathology reports in a location hospital registry; 100 patients were mailed invitation letters from their physician and contacted for participation, from which $76 \%$ agreed to join the study. A comparison group of women $(n=76)$ were recruited from health fairs which were geared to provide cancer screening services to residents in the Washington, DC Metropolitan Area. Women were eligible for the comparison group if they were African American between 40-50 years old, reported having had a mammogram within the last year with benign results, and not being treated for depression or a mental illness. Women recruited from health fairs scheduled an in-person interview with the research assistant. All recruited participants were consented by a trained research assistant at university study offices where participants completed a self-administered survey which took approximately 90 minutes to complete [36]. No monetary incentives were provided.

\section{Instruments}

The outcome variable was depressive symptomatology and major predictor variables were ego strength, social support, stage of breast cancer, and demographic factors. 
Outcome measure-The Beck Depression Inventory- Short Form, was used to assess depression symptomatology. This tool is widely used and includes 13 -items that assess the severity of current affective, motivational, and behavioral symptoms of depression in psychiatrically diagnosed patients and in normal populations (alpha range 0.74 to 0.95 ) $[37,38]$. In the current study alpha $=0.89$. Each item consists of a list of four statements organized in increasing severity about a particular symptom of depression and a 9-10 cut-off point is suggested for medical patients [39].

Predictors-The Barron's Ego Strength Scale (MMPI-2) includes 52 items that measure aspects of effective functioning, adaptability, and personal resourcefulness. The scale has demonstrated good reliability (alpha $=0.66$ ) [40], also in this study (alpha=0.70). Emotional and tangible support from networks was measured using the Norbeck Social Support Questionnaire (NSSQ). NSSQ assesses structural properties (e.g. size of the network) and functional properties (emotional and tangible support). Respondents answer questions regarding: (1) a list of significant people in one's life; (2) length of association and frequency of contact with these individuals; (3) the degree to which each person provides emotional and tangible support; and (4) recent losses of supportive relationships. At least three scores are yielded from the NSSQ: a total functional score, a total network score, and a total loss score. Reported internal consistency Cronbach alpha coefficients for the Norbeck Social Questionnaire range from 0.89 to 0.98 [41,42]. In this study Cronbach alpha coefficient was 0.93 .

Other variables included on the survey were age, marital status, income level, occupation, education, family history of breast cancer (yes vs. no). Breast cancer (from stage I to stage IV) was captured for breast cancer patients.

\section{Statistical Analysis}

Descriptive statistics were used to describe sample characteristics of the study participants. Independent sample t-test, chi square test, and analyses of variance (ANOVA) were used to examine whether depression symptoms varied by the various groups. Post-hoc procedures were performed for pairwise comparisons. Two multiple regression models (with a stepwise selection method) were fit to the data to identify correlates of depression symptoms among women with breast cancer and among disease free women. Coefficient of Determination $\left(\mathrm{R}^{2}\right)$ was reported to estimate the amount of variation in depression symptoms scale explained by the explanatory variables in the model. All data analysis was conducted using SAS.

\section{Results \\ Sample Characteristics}

The sample consisted of 152 African American women between the ages of 40 and 50 years, with a mean age of $44.0(\mathrm{SD}=3.11)$. Both women with breast cancer and those in the comparison group had a fairly high level of education, with $55.3 \%$ and $72.6 \%$, respectively, having some college education or higher. Similarity, $48.7 \%$ and $53.9 \%$, respectively, were employed in professional positions. Table 1 provides additional demographic information. No significant differences $(\mathrm{p}>0.05)$ between cases and comparison groups were found in demographic variables (marital status, income, occupation, and education).

As expected, depression was statistically higher in cases (mean=11.5, $\mathrm{SD}=5.0$ ) than in the comparison group (mean=3.9, $\mathrm{SD}=3.8)$. Additionally, total functioning $\left(\mathrm{t}_{150 \mathrm{df}}=(2.26)\right.$ was significantly lower among cases compared to the comparison group $\left(t_{150 d f}=4.04, p<0.001\right)$ (Table 2). 
Depressive symptoms varied according to the woman's stage of breast cancer, which emerged as the only significant main effect $F(1,72)=66.5$, $p<0.0001$. Mean levels of depression increased significantly as stage of breast cancer advanced: Stage I (mean=5.53, $\mathrm{SD}=1.35$ ); Stage II (mean=9.04, SD=2.28); Stage III (mean=14.16, SD=2.27); and Stage IV (mean $=19.25, \mathrm{SD}=1.86$ ). Post hoc comparisons (Scheffe') indicated that depression means in each stage significantly differed from each other.

Tables 3 and 4 display results from the stepwise multiple regression analyses. Among breast cancer cases, stage of disease and age were positively related to depression. Both factors were the only independent predictors of depression and explained $84 \%$ of the variance. Among women in the comparison group, ego strength and tangible support were independent negative predictors of depressive symptoms explaining $32 \%$ of the variance.

\section{Discussion}

To our knowledge, this is among the first studies to compare levels of depressive symptomatology in African American women with and without breast cancer while examining the impact of internal characteristics and social support. We found that African American women with breast cancer reported greater levels of depression than women without cancer from community settings and rates in this group were higher than found in a recent study of mostly White breast cancer patients using the same screening tool (e.g., BDI) [43]. We also found that women with breast cancer reported lower levels of functioning compared to women without cancer. These findings underscore the importance of recent guidelines to screen routinely for psychological morbidity in breast cancer patients. Compared to their White counterparts, relatively little is known about adaptation in African American survivors. While previous research demonstrated that individuals with cancer have greater levels of psychiatric illness, especially depression when compared to the general population [44-49] we have now expanded this knowledge to African American breast cancer survivors.

We found that breast cancer stage and age were independently associated with depressive symptoms in African American woman with breast cancer accounting for a significant amount of the explained variance. Our finding that older age was associated with higher levels of depression is contrary to some reports that examined anxiety and depression and found that depression and anxiety were higher in younger African American women [50]. One explanation for this difference may be that the current study had a more narrow age range and thus did not allow for comparisons between very young or very old African American women. [51,52]. Overall the sample could be regarded as "younger" in general since participants were $\mathbf{5 0}$ years of age and data suggests that compared to older breast cancer survivors, younger survivors report more psychological problems and adjustment difficulties [53].

Our findings point to important implications for long-term well-being in African American survivors because they are more likely to have an earlier age of onset of breast cancer compared to White women [35]. While there is limited empirical data regarding reasons for the depressive symptoms in African American women, younger women may have more concerns about taking care of their children, future child-bearing and sexuality than their older counterparts [53-55]. In addition to age, certain contextual factors may exacerbate these issues and increase vulnerability to depressive symptomatology in African American women compared to their White counterparts such as financial barriers, lower socioeconomic status, and access to mental health services [56]. More information is needed about the particular problems and/or concerns of younger African American breast cancer patients as well as interventions to address these issues. 
A higher stage of breast cancer, was associated with higher levels of depressive symptoms, which have been reported in other populations [57,58]. These findings are consistent with previous research demonstrating relatively high levels of psychiatric distress (depression, anxiety) in patients with advanced stages of breast cancer [59,60]. Fulton's study [59] examined 80 women diagnosed with advance stage breast cancer from initial diagnosis through a 16-month period in an effort to monitor levels of depression and anxiety along with identifying mood disturbance. When using cut off scores on the Hospital Anxiety and Depression Scale (HADS), Fulton found that a relatively large proportion of the sample fell into the borderline and cases ranged for both depression (31\%) and anxiety (39\%). In contrast, a cross-sectional study conducted by Kissane and colleagues [60] found high rates of psychiatric distress (depression) and disturbances in a sample of 303 women with earlystage breast cancer. These studies, however, did not compare depressive symptoms across breast cancer stage.

A plausible explanation for the relationship between clinical stage and depression is that the clinical aspects of the disease (i.e., stage of cancer) may be more robust predictors of depression than psychosocial variables included in this study, thus not accounting for significant amounts of the explained variance. Although previous research has not specifically examined predictors of depression in African American women with breast cancer, ego strength and multi-dimensions of social support have been related to psychological adjustment to breast cancer $[15,16,19,61,62]$. The consistency of these findings across research designs and with different samples gives strength to the conclusion that associations exist between ego strength, social support, and depression. However, the fact that stage of breast cancer did emerge as the best predictor of depression in the present study underscores the important role that stage of disease plays in the psychological functioning of women within the sample.

While ego strength and the various social support variables seem to be non-significant predictors of depressive symptoms for women with breast cancer, ego strength and tangible support accounted for $32 \%$ of the total explained variance in depressive symptoms in the comparison group. One possible explanation for the difference between the two groups (breast cancer and disease free) is that simply the clinical condition for breast cancer is more stable and robust predictor of depressive symptoms than intra-psychic characteristics of the individual (e.g. level of adaptability) and socio-cultural factors (e.g. social support). However, an alternative explanation may be that other personality factors (e.g. distressed Type D personality) that were not explored in this investigation could possibly predict depression. For example, research has shown that Type D personality, also called distressed personality, has been linked with depression in other clinical populations (i.e. cardiac patients) [63]. Future studies in African American patients that include measures of personality traits such as Type D may be useful.

Another explanation of the lack of association between social support and depression in the breast cancer group may rely in the inadequacy of the instrument to capture all the relevant types of social support for this group. Current measures of social support have often been developed and validated in White middle class populations and might not include some types of social support deemed to be important for ethnic minorities or specific subpopulations, such as breast cancer patients [64]. For instance, in a qualitative study that explored perceptions and experiences of social support in African American women with breast cancer, Hamilton and colleagues [64] found various types of emotional support (e.g. presence of others, engaging in distracting activities) and tangible support (e.g. offers of prayers, assistance to continue religious practices) not included in Norbecks' emotional and tangible support subscales. Furthermore, informational support, (e.g. getting information about what to expect, validating the information received by the doctors), was found to be 
very relevant among African American breast cancer women, but it was a dimension of support not covered by Norbecks' social support questionnaire [41,42]. Additionally, structural properties of the network included in the survey, such as the size of the network, might have a different impact on mental health than expected in breast cancer patients compared to the comparison group. For instance, Ashida and colleagues [20] found that for younger breast cancer women a reduction of network size was associated with better psychological adjustment. Thus, further research to understand the impact of various types of social support in mental health for specific subpopulations is warranted.

Therefore, it is important to emphasize that one should not discount the valuable role that personality characteristics of the individuals and the social support available to these individuals can play in the psychological functioning of women with breast cancer given the findings regarding the benefits social support and support groups. In addition to support groups, cancer providers have and important role of providing emotional and social support to women diagnosed with breast cancer [13]. Thus, future studies should examine healthcare interactions (e.g., patient-provider communication) and access barriers as other potential predictors of psychological morbidity in recently diagnosed patients $[65,66]$.

While it is well noted that many African American women have strong spiritual coping $[10,67]$ this does not preclude the need for psychosocial support during cancer treatment. The stress and fear associated with the diagnosis of breast cancer may indeed trigger a depressive response or reaction. Additionally, it is likely that African American breast cancer patients, especially those of lower socioeconomic status, encounter economic as well as other barriers to cancer care [68] which has been shown to be associated with depressive symptomatology in other minority groups $[58,69]$.

Currently little is known about the mental health referral process for African American women with breast cancer. However, limited data suggest that African American women are less likely to seek and/or receive necessary mental health services than their White counterparts $[65,66,70,71]$. Thus receipt of appropriate psychosocial assessments and mental health referral warrants attention for this group. Based on our data, greater efforts should be implemented to offer psychosocial support services especially to younger African American women with breast cancer. Because comprehensive supportive care may not be readily available to all women with breast cancer, ensuring interdisciplinary collaborations between oncologists and mental health professionals is one practical step in this direction.

The study had certain limitations. Due to the cross-sectional nature of the study we cannot determine the causal direction of the association between depression symptoms and the predictors. Women were recruited in urban areas and eligible participants were between 40-50 years old, thus results may not generalize to younger or older populations or to women that live in rural areas. We did not capture information about stage of treatment which prevented us from analyzing the impact that stage of treatment may have had on depression levels. Nevertheless, this study is among the first to compare cases and controls in African American breast cancer patients adding to the paucity of empirical data about correlates of depression and on the internal consistency and reliability of the selected measures for the African American female population. As such, this research begins to close the gaps in knowledge about the general psychological presentation of African American women with breast cancer.

\section{Acknowledgments}

This research was funded by grants from the American Cancer Society \# MRSGT 06 -132-01 CPPB and NIH Health Disparities Loan Repayment Award 2L60MD000291-02. 


\section{References}

1. Jemal A, Siegel R, Ward E, Hao Y, Xu J, Thun MJ. Cancer statistics, 2009. CA Cancer J Clin. 2009; 59:225-249. [PubMed: 19474385]

2. Jatoi I, Anderson WF, Rao SR, Devesa SS. Breast cancer trends among black and white women in the United States. J Clin Oncol. 2005; 23:7836-7841. [PubMed: 16258086]

3. Fawzy FI, Fawzy NW, Arndt LA, Pasnau RO. Critical review of psychosocial interventions in cancer care. Arch Gen Psychiatry. 1995; 52:100-113. [PubMed: 7848046]

4. Wong-Kim EC, Bloom JR. Depression experienced by young women newly diagnosed with breast cancer. Psychooncology. 2005; 14:564-573. [PubMed: 15543537]

5. Evans DL, Charney DS, Lewis L, Golden RN, Gorman JM, Krishnan KR, et al. Mood disorders in the medically ill: scientific review and recommendations. Biol Psychiatry. 2005; 58:175-189. [PubMed: 16084838]

6. Hjerl K, Andersen EW, Keiding N, Mouridsen HT, Mortensen PB, Jorgensen T. Depression as a prognostic factor for breast cancer mortality. Psychosomatics. 2003; 44:24-30. [PubMed: 12515834]

7. Fann JR, Thomas-Rich AM, Katon WJ, Cowley D, Pepping M, McGregor BA, et al. Major depression after breast cancer: a review of epidemiology and treatment. Gen Hosp Psychiatry. 2008; 30:112-126. [PubMed: 18291293]

8. Jacobsen PB, Wagner LI. A new quality standard: the integration of psychosocial care into routine cancer care. J Clin Oncol. 2012; 30:1154-1159. [PubMed: 22412134]

9. Moore RJ. African American women and breast cancer: notes from a study of narrative. Cancer Nurs. 2001; 24:35-42. quiz 43. [PubMed: 11219421]

10. Culver JL, Arena PL, Antoni MH, Carver CS. Coping and distress among women under treatment for early stage breast cancer: comparing African Americans, Hispanics and non-Hispanic Whites. Psychooncology. 2002; 11:495-504. [PubMed: 12476431]

11. Deshields T, Tibbs T, Fan MY, Taylor M. Differences in patterns of depression after treatment for breast cancer. Psychooncology. 2006; 15:398-406. [PubMed: 16100708]

12. Golden-Kreutz DM, Andersen BL. Depressive symptoms after breast cancer surgery: relationships with global, cancer-related, and life event stress. Psychooncology. 2004; 13:211-220. [PubMed: 15022156]

13. Davey MP, Kissil K, Nino A, Tubbs CY. "They paid no mind to my state of mind": African American breast cancer patients' experiences of cancer care delivery. J Psychosoc Oncol. 2010; 28:683-698. [PubMed: 21058163]

14. Goldstein, E. Ego psychology and social work practice. Free Press; New York: 1995.

15. Weisman AD. Early diagnosis of vulnerability in cancer patients. Am J Med Sci. 1976; 271:187196. [PubMed: 1266889]

16. Sobel HJ, Worden JW. The MMPI as a predictor of psychosocial adaptation to cancer. J Consult Clin Psychol. 1979; 47:716-724. [PubMed: 500907]

17. Edgar L, Rosberger Z, Nowlis D. Coping with cancer during the first year after diagnosis. Assessment and intervention. Cancer. 1992; 69:817-828.

18. Berkman LLF. From social integration to health: Durkheim in the new millennium. Soc Sci Med. 2000; 51:843-857. [PubMed: 10972429]

19. Al-Azri M, Al-Awisi H, Al-Moundhri M. Coping with a diagnosis of breast cancer-literature review and implications for developing countries. Breast J. 2009; 15:615-622. [PubMed: 19686231]

20. Ashida S, Palmquist AE, Basen-Engquist K, Singletary SE, Koehly LM. Changes in female support network systems and adaptation after breast cancer diagnosis: differences between older and younger patients. Gerontologist. 2009; 49:549-559. [PubMed: 19465702]

21. Beder J. Perceived social support and adjustment to mastectomy in socioeconomically disadvantaged black women. Soc Work Health Care. 1995; 22:55-71. [PubMed: 8658319]

22. Chantler M, Podbilewicz-Schuller Y, Mortimer J. Change in need for psychosocial support for women with early stage breast cancer. J Psychosoc Oncol. 2005; 23:65-77. [PubMed: 16492652] 
23. Gass JS, Weitzen S, Clark M, Dizon DS. Defining social support systems for women with breast cancer. Am J Surg. 2007; 194:501-503. [PubMed: 17826065]

24. Kang SH, Bloom JR. Social support and cancer screening among older black Americans. J Natl Cancer Inst. 1993; 85:737-742. [PubMed: 8478960]

25. Koopman C, Hermanson K, Diamond S, Angell K, Spiegel D. Social support, life stress, pain and emotional adjustment to advanced breast cancer. Psychooncology. 1998; 7:101-111. [PubMed: 9589508]

26. Kroenke CH, Kubzansky LD, Schernhammer ES, Holmes MD, Kawachi I. Social networks, social support, and survival after breast cancer diagnosis. J Clin Oncol. 2006; 24:1105-1111. [PubMed: 16505430]

27. Lee MK, Park S, Lee ES, Ro J, Kang HS, Shin KH, et al. Social support and depressive mood 1 year after diagnosis of breast cancer compared with the general female population: A prospective cohort study. Support.Care Cancer. 2011; 19:1379-1392. [PubMed: 20676695]

28. Liao MMN. Effect of supportive care on the anxiety of women with suspected breast cancer Supportive care for women with suspected breast cancer. J Adv Nurs. 2010; 66:49-59. [PubMed: 19968726]

29. Kornblith AB, Herndon JE 2nd, Zuckerman E, Viscoli CM, Horwitz RI, Cooper MR, et al. Social support as a buffer to the psychological impact of stressful life events in women with breast cancer. Cancer. 2001; 91:443-454. [PubMed: 11180093]

30. Alloway R, Bebbington P. The buffer theory of social support--a review of the literature. Psychol Med. 1987; 17:91-108. [PubMed: 3575581]

31. Den Oudsten BL, Van Heck GL, Van der Steeg AF, Roukema JA, De Vries J. Personality predicts perceived availability of social support and satisfaction with social support in women with early stage breast cancer. Support Care Cancer. 2010; 18:499-508. [PubMed: 19685345]

32. Simpson JS, Carlson LE, Beck CA, Patten S. Effects of a brief intervention on social support and psychiatric morbidity in breast cancer patients. Psychooncology. 2002; 11:282-294. [PubMed: 12203742]

33. Bourjolly JJN. Similarities in Coping Strategies but Differences in Sources of Support Among African American and White Women Coping with Breast Cancer. J Psychosoc Oncol. 2001; 19:17-38.

34. NCC N practice guidelines for the management of psychosocial distress. National Comprehensive Cancer Network. Oncology (Huntingt). 1999; 13:113-147. [PubMed: 10370925]

35. Shavers VL, Harlan LC, Stevens JL. Racial/ethnic variation in clinical presentation, treatment, and survival among breast cancer patients under age 35. Cancer. 2003; 97:134-147. [PubMed: 12491515]

36. Ford, LA. Unpublished Doctoral Dissertation. 2002. Predictors of psychological functioning in African American women with breast cancer.

37. Beck AT, Rial WY, Rickels K. Short form of depression inventory: cross-validation. Psychol Rep. 1974; 34:1184-1186. [PubMed: 4424377]

38. Beck AT, Steer RA. Internal consistencies of the original and revised Beck Depression Inventory. J Clin Psychol. 1984; 40:1365-1367. [PubMed: 6511949]

39. Furlanetto LM, Mendlowicz MV, Romildo Bueno J. The validity of the Beck Depression Inventory-Short Form as a screening and diagnostic instrument for moderate and severe depression in medical inpatients. J Affect Disord. 2005; 86:87-91. [PubMed: 15820275]

40. Schuldberg D. Ego-strength revised: a comparison of the MMPI-2 and MMPI-1 versions of the Barron Ego-strength scale. J Clin Psychol. 1992; 48:500-505. [PubMed: 1517443]

41. Norbeck JS, Lindsey AM, Carrieri VL. The development of an instrument to measure social support. Nurs Res. 1981; 30:264-269. [PubMed: 7027185]

42. Norbeck JS, Lindsey AM, Carrieri VL. Further development of the Norbeck Social Support Questionnaire: normative data and validity testing. Nurs Res. 1983; 32:4-9. [PubMed: 6549842]

43. Eskelinen M, Ollonen P. Beck Depression Inventory (BDI) in patients with breast disease and breast cancer: a prospective case-control study. In Vivo. 2011; 25:111-116. [PubMed: 21282743] 
44. Bell RJ, Lijovic M, La China M, Schwarz M, Fradkin P, Bradbury J, et al. Psychological wellbeing in a cohort of women with invasive breast cancer nearly 2 years after diagnosis. Support Care Cancer. 2010; 18:921-929. [PubMed: 19707799]

45. Derogatis LR, Morrow GR, Fetting J, Penman D, Piasetsky S, Schmale AM, et al. The prevalence of psychiatric disorders among cancer patients. JAMA. 1983; 249:751-757. [PubMed: 6823028]

46. Karademas EC, Argyropoulou K, Karvelis S. Psychological symptoms of breast cancer survivors: a comparison with matched healthy controls and the association with cancer-related stress and coping. J Psychosoc Oncol. 2007; 25:59-74. [PubMed: 19341014]

47. Lehto US, Ojanen M, Dyba T, Aromaa A, Kellokumpu-Lehtinen P. Baseline psychosocial predictors of survival in localised breast cancer. Br J Cancer. 2006; 94:1245-1252. [PubMed: 16670704]

48. Massie MJ, Holland JC. Depression and the cancer patient. J Clin Psychiatry. 1990; 51(Suppl):127. discussion 18-9. [PubMed: 2195008]

49. Spiegel D. Cancer and depression. Br J Psychiatry Suppl. 1996; (30):109-116. [PubMed: 8864156]

50. Sheppard VB, Harper FW, Davis K, Hirpa F, Makambi K. <br />The Importance of Contextual Factors and Age in Association with Anxiety and Depression in Black Breast Cancer Patients. Psychooncology. Submitted.

51. Ell K, Sanchez K, Vourlekis B, Lee PJ, Dwight-Johnson M, Lagomasino I, et al. Depression, correlates of depression, and receipt of depression care among low-income women with breast or gynecologic cancer. J Clin Oncol. 2005; 23:3052-3060. [PubMed: 15860863]

52. Osborne RHRH. Age-specific norms and determinants of anxiety and depression in 731 women with breast cancer recruited through a population-based cancer registry. European journal of cancer (1990). 2003; 39:755-762.

53. Kornblith AB, Powell M, Regan MM, Bennett S, Krasner C, Moy B, et al. Long-term psychosocial adjustment of older vs younger survivors of breast and endometrial cancer. Psychooncology. 2007; 16:895-903. [PubMed: 17245695]

54. Siegel KDK. Age-Related Distress Among Young Women with Breast Cancer. J Psychosoc Oncol. $1999 ; 17: 1-20$.

55. Connell SS. Issues and concerns of young Australian women with breast cancer. Supportive care in cancer. 2006; 14:419-426. [PubMed: 16463036]

56. Das AK, Olfson M, McCurtis HL, Weissman MM. Depression in African Americans: breaking barriers to detection and treatment. J Fam Pract. 2006; 55:30-39. [PubMed: 16388764]

57. Huang CY, Guo SE, Hung CM, Shih SL, Lee LC, Hung GC, et al. Learned resourcefulness, quality of life, and depressive symptoms for patients with breast cancer. Oncol Nurs Forum. 2010; 37:E280-7. [PubMed: 20591791]

58. Popoola AO, Adewuya AO. Prevalence and correlates of depressive disorders in outpatients with breast cancer in Lagos, Nigeria. Psychooncology. 2012; 21:675-679. [PubMed: 21462281]

59. Fulton $\mathrm{C}$. The prevalence and detection of psychiatric morbidity in patients with metastatic breast cancer. Eur J Cancer Care (Engl). 1998; 7:232-239. [PubMed: 9919110]

60. Kissane DW, Clarke DM, Ikin J, Bloch S, Smith GC, Vitetta L, et al. Psychological morbidity and quality of life in Australian women with early-stage breast cancer: a cross-sectional survey. Med J Aust. 1998; 169:192-196. [PubMed: 9734576]

61. Maly RC, Umezawa Y, Leake B, Silliman RA. Mental health outcomes in older women with breast cancer: impact of perceived family support and adjustment. Psychooncology. 2005; 14:535545. [PubMed: 15493064]

62. Manning-Walsh J. Social support as a mediator between symptom distress and quality of life in women with breast cancer. J Obstet Gynecol Neonatal Nurs. 2005; 34:482-493.

63. Pedersen SS, van Domburg RT, Theuns DA, Jordaens L, Erdman RA. Type D personality is associated with increased anxiety and depressive symptoms in patients with an implantable cardioverter defibrillator and their partners. Psychosom Med. 2004; 66:714-719. [PubMed: 15385696]

64. Hamilton JB, Sandelowski M. Types of social support in African Americans with cancer. Oncol Nurs Forum. 2004; 31:792-800. [PubMed: 15252433] 
65. Royak-Schaler R, Passmore SR, Gadalla S, Hoy MK, Zhan M, Tkaczuk K, et al. Exploring patientphysician communication in breast cancer care for African American women following primary treatment. Oncol Nurs Forum. 2008; 35:836-843. [PubMed: 18765331]

66. Sheppard VB, Adams IF, Lamdan R, Taylor KL. The role of patient-provider communication for black women making decisions about breast cancer treatment. Psychooncology. 2011; 20:13091316. [PubMed: 20941804]

67. Henderson PD, Gore SV, Davis BL, Condon EH. African American women coping with breast cancer: a qualitative analysis. Oncol Nurs Forum. 2003; 30:641-647. [PubMed: 12861324]

68. Ell K, Sanchez K, Vourlekis B, Lee PJ, Dwight-Johnson M, Lagomasino I, et al. Depression, correlates of depression, and receipt of depression care among low-income women with breast or gynecologic cancer. J Clin Oncol. 2005; 23:3052-3060. [PubMed: 15860863]

69. Heilemann MV, Lee KA, Kury FS. Strengths and vulnerabilities of women of Mexican descent in relation to depressive symptoms. Nurs Res. 2002; 51:175-182. [PubMed: 12063416]

70. Conner KO, Lee B, Mayers V, Robinson D, Reynolds CF, Albert S, et al. Attitudes and beliefs about mental health among African American older adults suffering from depression. J Aging Stud. 2010; 24:266-277. [PubMed: 21423819]

71. Gonzalez HM, Vega WA, Williams DR, Tarraf W, West BT, Neighbors HW. Depression care in the United States: too little for too few. Arch Gen Psychiatry. 2010; 67:37-46. [PubMed: 20048221]

J Cancer Surviv. Author manuscript; available in PMC 2014 September 01. 
Table 1

Characteristics of the Study Population by Disease Status $(\mathrm{N}=152)$

\begin{tabular}{|c|c|c|c|c|}
\hline \multirow[t]{2}{*}{ Characteristics } & \multicolumn{2}{|c|}{$\begin{array}{l}\text { Breast } \\
\text { Cancer } \\
(\mathrm{N}=76)\end{array}$} & \multicolumn{2}{|c|}{$\begin{array}{l}\text { Disease } \\
\text { Free } \\
(\mathbf{N}=76)\end{array}$} \\
\hline & $\mathrm{N}$ & $\%$ & $\mathrm{~N}$ & $\%$ \\
\hline \multicolumn{5}{|l|}{ Marital Status } \\
\hline Single & 22 & 28.9 & 18 & 23.7 \\
\hline Married & 21 & 27.6 & 27 & 35.5 \\
\hline Separated & 9 & 11.8 & 9 & 11.8 \\
\hline Divorced & 19 & 25.0 & 16 & 21.1 \\
\hline Widowed & 5 & 6.6 & 6 & 7.9 \\
\hline \multicolumn{5}{|l|}{ Income Level } \\
\hline$<\$ 15,000$ & -- & -- & 2 & 2.6 \\
\hline$\$ 15,000-\$ 19,999$ & 2 & 2.6 & 9 & 11.8 \\
\hline$\$ 20,000-\$ 29,999$ & 24 & 31.6 & 26 & 34.2 \\
\hline$\$ 30,000-\$ 39,999$ & 27 & 35.5 & 19 & 25.0 \\
\hline$\$ 40,000-\$ 69,999$ & 17 & 22.4 & 16 & 21.1 \\
\hline$\$ 70,000-\$ 99,999$ & 2 & 2.6 & 3 & 3.9 \\
\hline 9-Prefer not to answer & 4 & 5.3 & 1 & 1.3 \\
\hline
\end{tabular}

Occupation

$\begin{array}{lllll}\text { Professional } & 37 & 48.7 & 41 & 53.9 \\ \text { Nonprofessional } & 36 & 47.4 & 35 & 46.1 \\ \text { Unemployed } & 2 & 2.6 & -- & -- \\ \text { No Answer } & 1 & 1.3 & -- & \text { B }\end{array}$

Education

$\begin{array}{lllll}\text { Less than high school } & -- & -- & 1 & 1.3 \\ \text { High school graduate } & 9 & 11.8 & 10 & 13.2 \\ \text { Vocational or technical } & 17 & 22.4 & 3 & 3.9 \\ \text { Some college } & 17 & 22.4 & 27 & 35.5 \\ \text { College graduate } & 24 & 31.6 & 27.7 & 35.5 \\ \text { Advanced Studies } & 1 & 1.3 & 2 & 2.6 \\ \text { Advanced Degree } & 8 & 10.5 & 6 & 7.9\end{array}$

Breast Cancer Stage

$\begin{array}{lllll}\text { Stage I } & 15 & 19.7 & -- & -- \\ \text { Stage II } & 25 & 32.9 & -- & - \\ \text { Stage III } & 24 & 31.6 & - & - \\ \text { Stage IV } & 12 & 15.8 & -- & -\end{array}$

Family History of Breast Cancer *

\begin{tabular}{lllll} 
Yes & 17 & 22.4 & 22 & 28.9 \\
No & 29 & 38.2 & 47 & 61.8 \\
Unknown & 30 & 39.5 & 7 & 9.2 \\
\hline
\end{tabular}

p $<0.01$ 
Table 2

Mean Comparison of Depressive Symptomatology, Support, Functioning and Network by Breast Cancer Disease Status

\begin{tabular}{lllll}
\hline & $\begin{array}{l}\text { Breast Cancer } \\
(\mathbf{N = 7 6 )}\end{array}$ & & $\begin{array}{l}\text { Disease Free } \\
(\mathbf{N = 7 6 )}\end{array}$ & \\
\hline Variables & $\mathbf{X}$ & SD & $\mathbf{X}$ & SD \\
\hline Depression & 11.5 & 5.0 & 3.9 & 3.8 \\
Ego Strength & 34.5 & 3.3 & 36.0 & 4.9 \\
$\begin{array}{l}\text { Emotional } \\
\text { Support }\end{array}$ & 66.6 & 33.1 & 90.2 & 43.0 \\
Tangible Support & 34.8 & 16.5 & 48.4 & 21.2 \\
$\begin{array}{l}\text { Total } \\
\text { Functioning }\end{array}$ & 101.4 & 49.4 & 138.6 & 63.3 \\
Total Network & 51.1 & 24.2 & 74.5 & 30.8 \\
Total Loss & 2.2 & 3.0 & 3.0 & 4.2 \\
\hline
\end{tabular}

Note: The scores on the ego strength range from 0-52; the Depression scale range from 0-39. The range of scores on the other variables vary since they were able to cite as many individuals as they wanted in their list of networks. 


\section{Table 3}

Stepwise Multiple Regression Model for Depressive Symptoms Regressed on Ego Strength, Social Support, Stage of Breast Cancer, Age, Marital Status and Education in Women with Breast Cancer

\begin{tabular}{lcccc}
\hline Variables Entered & Cumulative Multiple R & R Square & Beta & F-Value \\
\hline Breast Cancer Stages & .91 & .83 & .912 & $358.12^{*}$ \\
Age & .92 & .84 & .11 & $190.87^{*}$ \\
\hline
\end{tabular}

p <.0001 Note: Analysis excluded emotional support. 


\section{Table 4}

Stepwise Multiple Regression Model for Depressive Symptoms Regressed on Age, Education, Marital Status, Ego Strength, Emotional Support and Aid Support in Disease Free Women

\begin{tabular}{lcccl}
\hline Variables Entered & Cumulative Multiple R & R Square & Beta & F-Value \\
\hline Ego Strength & .52 & .27 & -.52 & $26.78^{*}$ \\
Tangible Support & .57 & .32 & -.24 & 17.21 \\
\hline
\end{tabular}

p $<.0001$ Note: The variables not entered were age, marital status, education, and emotional support 